\title{
STRUCTURE, DESIGN AND CONSTRUCTION OF A STEEL ORTHOTROPIC BRIDGE IN SOFIA
}

\author{
D. Partov ${ }^{1, *}$ and D. Dinev ${ }^{2, \#}$ \\ ${ }^{1}$ Assoc. Professor, Higher School of Construction Engineering "L. Karavelov", Bulgaria \\ * (Corresponding author: E-mail: partov@vsu.bg) \\ ${ }^{2}$ Assist. Professor, Univ. of Architecture, Civil Engineering and Geodesy, Bulgaria \\ ${ }^{\#}$ This paper is dedicated to assoc. prof. B. Bankov for his numerous contributions \\ to the bridge design and construction in Bulgaria
}

Received: 30 August 2006; Revised: 5 April 2007; Accepted: 22 June 2007

\begin{abstract}
In this paper the conceptual design and technology of construction of a steel orthotropic $90 \mathrm{~m}$ long bridge in Sofia, Bulgaria is presented. The steel bridge is part of a multi-span reinforced concrete (R/C) bridge with a total length of $2114 \mathrm{~m}$, a total width of $21.5 \mathrm{~m}$ and an average height above the ground of about $10 \mathrm{~m}$. In transverse direction the orthotropic bridge is built with two individual parallel triple-box decks for two-way traffic. Each deck has a $7.5 \mathrm{~m}$ wide roadway with two lanes. The bridge is analysed as a frame structure using the finite element method. The design parameters of the bridge are verified by static and dynamic tests.
\end{abstract}

Keywords: Steel bridge, orthotropic plate, box girder

\section{INTRODUCTION}

In the beginning of the 90's, in Sofia, the capital of Bulgaria arose the necessity for a long bridge connecting the center of the city to the airport. For this purpose a steel-reinforced concrete bridge was designed and constructed with a total length of $2114 \mathrm{~m}$, a width of $21.5 \mathrm{~m}$ and a height above ground of about $10 \mathrm{~m}$. The bridge is located in a densely populated urban environment.

This important, effective and aesthetic bridge serves as a connection between the busiest input-output highway and the airport of Sofia. It ensures a convenient access to some highways, railways, streets and the airport. As a result of this requirement, the erection of the reinforced concrete bridge is not allowed to cross the railway between Sofia and Varna. So, a $90 \mathrm{~m}$ long middle steel part was designed to cover two spans of $45 \mathrm{~m}$ each in the multi-span bridge structure (see Figure 1).

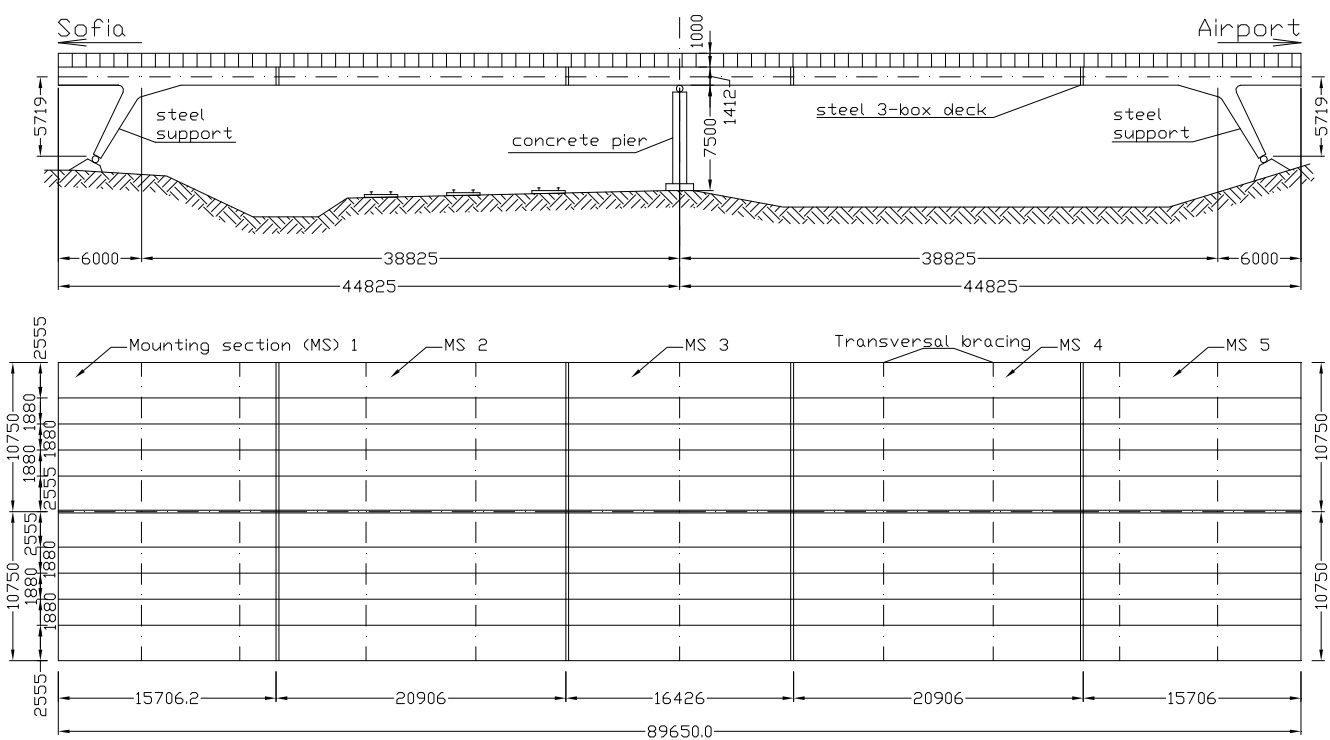

Figure 1. Longitudinal Cross-section and Top View of the Separate Sections 


\section{GENERAL DESCRIPTION OF THE BRIDGE STRUCTURE}

In longitudinal direction the bridge consists of two separate parallel steel structures with a total length of $89.650 \mathrm{~m}$. Each of the structures is $10.75 \mathrm{~m}$ wide and has a $7.5 \mathrm{~m}$ wide roadway with two lanes. The steel part of the bridge is placed in a horizontal curve with a radius of $1000 \mathrm{~m}$. In transverse direction the west deck of the bridge has a bilateral slope to vertical of $2 \%$ and the east deck has variable slopes between $0.319 \%$ and $2 \%$. The deck has a slightly descending slope of $0.10 \%$ along its length in the direction of the Airport because of the vertical profile of the road. The maximum distance from the upper level of the deck to the ground is about $7.5 \mathrm{~m}$. There is a longitudinal gap between adjacent decks.

The cross-section of each of these parallel parts is formed by triple-box structures with four vertical main girders. The girders are required by the longitudinal load distribution and the distances between them are $1880 \mathrm{~mm}$ (see Figure 2).

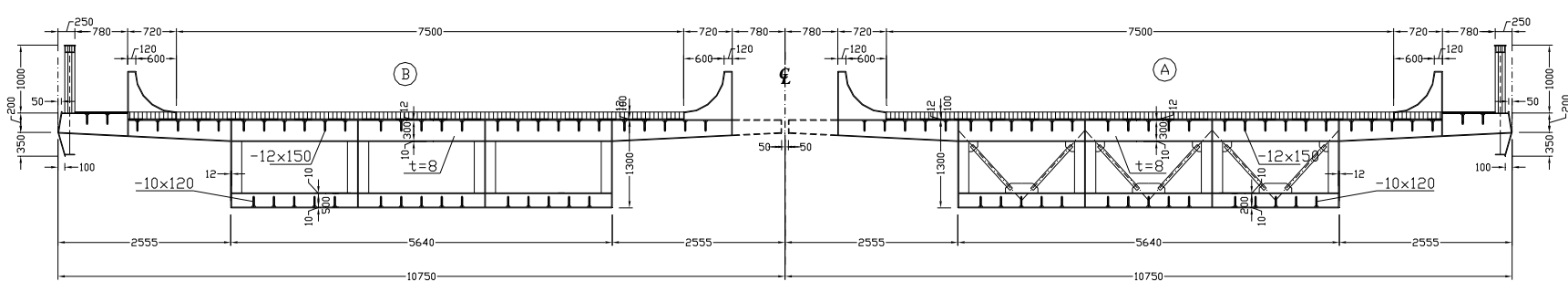

Figure 2. Cross-section of the Bridge

In the area of the transition ramp the bottom plate of the box cross-section is formed as a 3-D surface parallel to the upper deck. This solution keeps a constant height of $1300 \mathrm{~mm}$ of the main girders. These details showed the complexity of the structural problems during the design and the construction of the bridge.

The box has a constant cross-section with height of $1300 \mathrm{~mm}$ along the total length of the span. These dimensions were required and limited by aesthetic considerations, because the steel part should fully follow the silhouette of the concrete part with the same height. This is a pioneer example of how a steel structure follows the dimensional requirements of the adjacent concrete structure.

The system of the bridge structure is a classical orthogonal anisotropic plate (orthotropic plate) (Cornelius [1], Hawranek and Steinhardt [2], Pelikan and Esslinger [3]).

In longitudinal direction the main girders are connected to each other by upper and lower transversal steel beams at intervals of $1493.3 \mathrm{~mm}$. The upper transversal steel beams are connected at the top by a $12 \mathrm{~mm}$ thick steel plate. The lower transversal beams are connected at the bottom by a $10 \mathrm{~mm}$ thick steel plate.

The upper steel orthotropic plate, with a constant thickness of $12 \mathrm{~mm}$, is stiffened with longitudinal flat ribs: - $12 \times 150 \mathrm{~mm}$, which went through the webs of the transversal beams. All flat stiffening ribs were welded under the carriageway and footway plate, as well as to the webs of the transversal beams. The distance between the axes of the longitudinal ribs is $313 \mathrm{~mm}$. All these components form the orthotropic deck of the bridge (see Figure 3). 


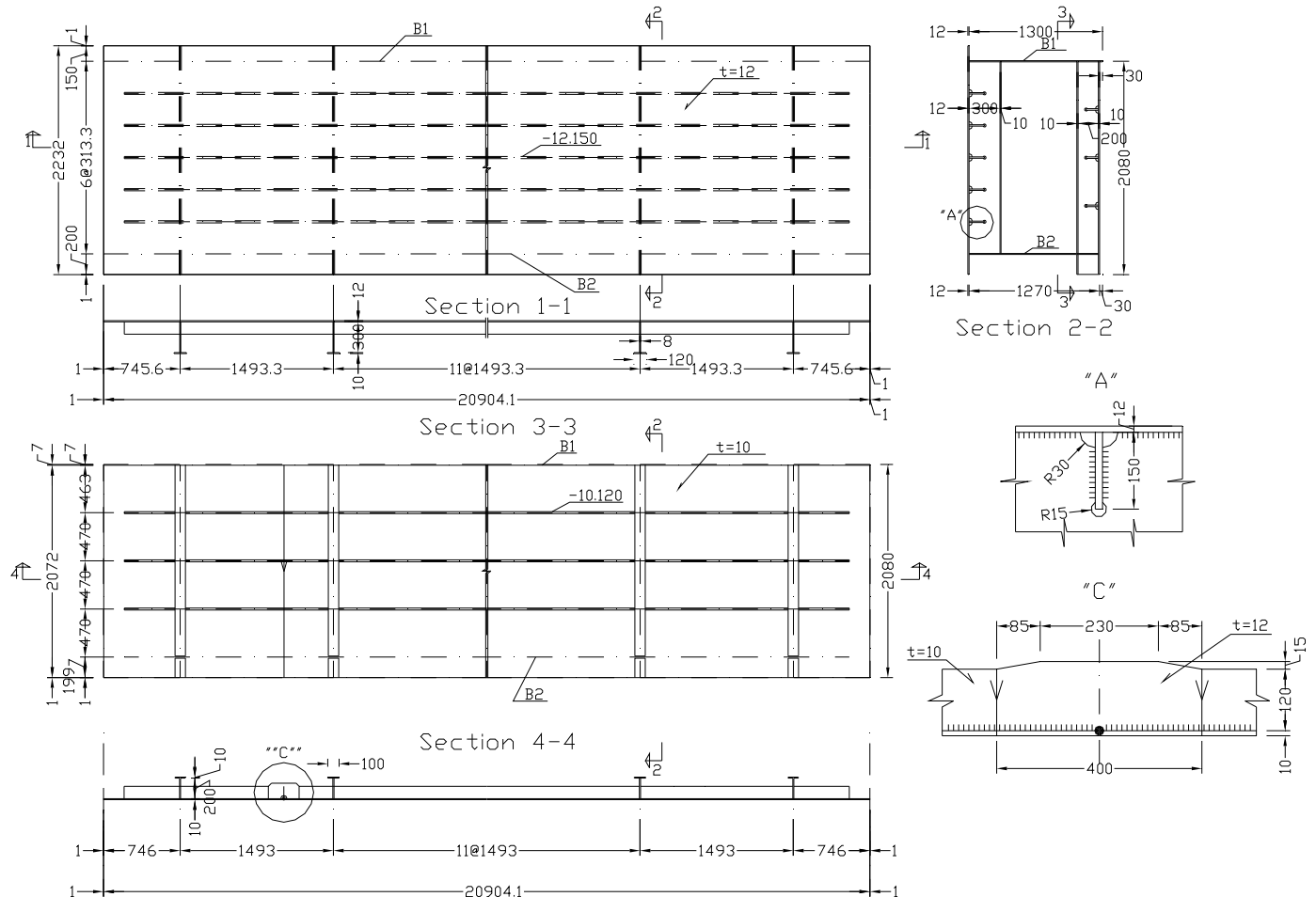

Figure 3. Steel Separate Deck Section - Orthotropic Plate Type

The upper transversal beams have “ $\perp$ ” cross-sections with web dimensions of $8 \times 300 \mathrm{~mm}$ and flange dimensions of $10 \times 120 \mathrm{~mm}$. The lower beams have " $T$ " cross-sections with web dimensions of $8 \times 200 \mathrm{~mm}$ and flange dimensions of $10 \times 100 \mathrm{~mm}$. The transversal beams ensure stability of the box cross-section.

The flat stiffening longitudinal ribs with dimensions of $10 \times 120 \mathrm{~mm}$ were welded to the bottom plate in order to achieve stability of the compressed bottom plate in the area of the middle support. The distances between them are $470 \mathrm{~mm}$.

The vertical webs of the triple-box girders with thickness of $12 \mathrm{~mm}$ are stiffened at every $1493 \mathrm{~mm}$ with vertical ribs of $10 \times 100 \mathrm{~mm}$ without flanges, which followed the results of structural analysis. These form the closed inner frame which stiffens the box cross-section.

For buckling analysis the vertical webs have dimensions of $12 \times 1300 \times 1493 \mathrm{~mm}$. Diagonal transverse bracings ( $\mathrm{L} 100 \times 100 \times 10 \mathrm{~mm}$ ) are placed at every $7.465 \mathrm{~m}$ into the plane frames in order to stiffen the structure against in-plane deformation. Transverse diaphragms are also placed at support regions.

The footway is designed as an orthotropic plate with a thickness of $6 \mathrm{~mm}$, stiffened with longitudinal flat ribs of $6 \times 60 \mathrm{~mm}$. The cross-sections of the transversal footway beams are “ $\perp$ ” shaped with webs $-8 \times 200 \mathrm{~mm}$ and flange of $10 \times 160 \mathrm{~mm}$. They were connected to the cantilevers of the transversal bridge beams by welding. The transversal slope of the footway was $1.5 \%$. The longitudinal board beam with a height of $350 \mathrm{~mm}$ connects the footway transversal beams. The footway has a $1000 \mathrm{~mm}$ high parapet.

The carriageway is equipped with safety borders, which have a concave surface with radius equal to $600 \mathrm{~mm}$. The two decks of the bridge are separated from each other by a $1560 \mathrm{~mm}$ wide gap. The space between the structures, at the level of the safety borders, is covered with a steel plate for security reasons. The steel plate is designed to carry the load of a car clash. The cantilevers of the 
transversal beams at the ends are extended to the longitudinal axis of the bridge to ensure the assembling of the dilatation joint.

In order to meet the requirement that the steel bridge should look like the concrete bridge, two "V"-shaped supports of varying cross-section were built (see Figures 4a and 4b).
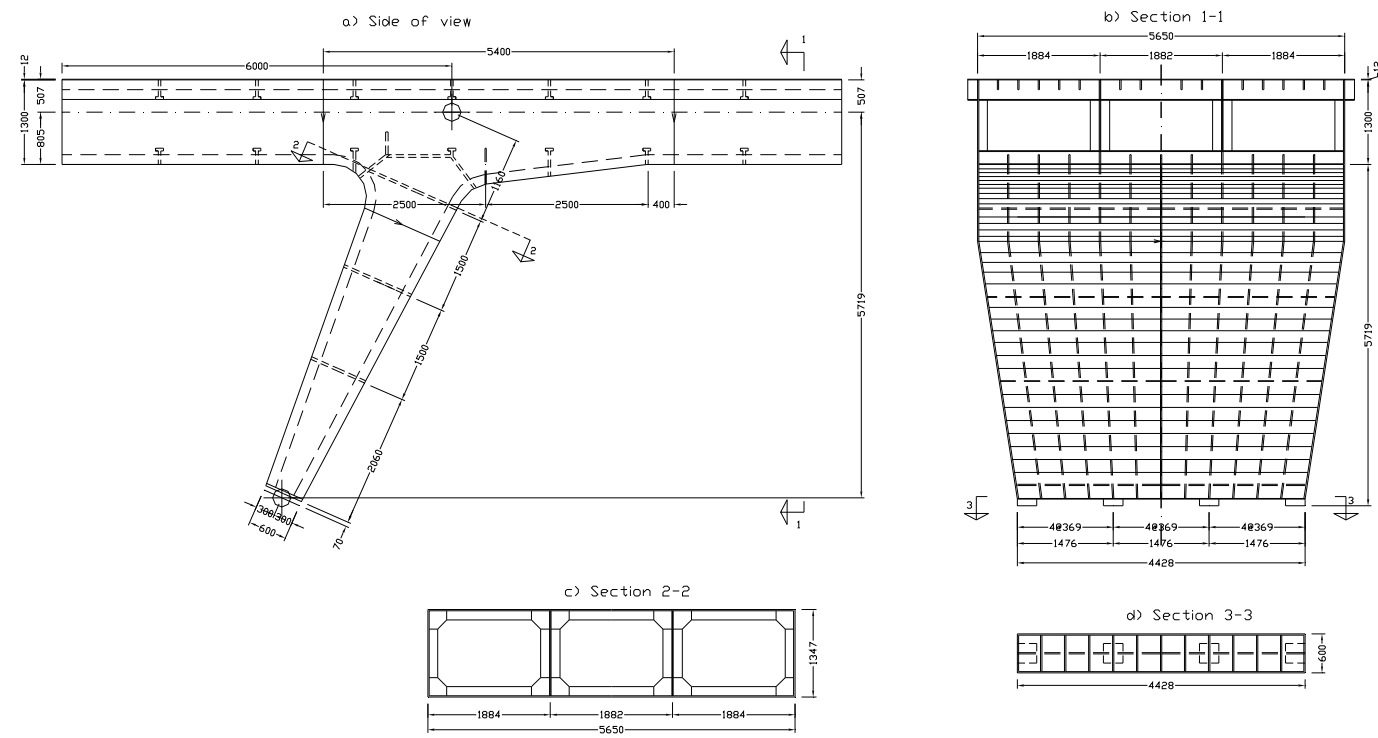

Figure 4. "V”- Shaped Steel Support

The steel supports of this part have triple-box cross-sections shown in Figure 4c. The "V"-shaped supports are rigidly connected to the decks and have rectangular cross-sections with dimensions $1347 \times 5650 \mathrm{~mm}$. The thickness of the steel sheets is $12 \mathrm{~mm}$. The other end of the supports is tied to the bases by cylindrical hinges. The cross-section at this level has dimensions $600 \times 4428 \mathrm{~mm}$ and is strengthened by four additional steel plates with dimensions $40 \times 400 \times 400 \mathrm{~mm}$ (Figure $4 \mathrm{~d}$ ). The supports were stiffened by transversal diaphragms placed at every $1500 \mathrm{~mm}$. The ribs of the lower deck were extended into the supports and form another orthotropic structure. The thickness of the steel sheets used for producing the ribs and the diaphragms was $10 \mathrm{~mm}$.

The two middle vertical R/C columns supporting the steel part of the bridge have varying rectangular cross-sections. They are bounded by elastomeric bearings to the steel bridge and by rigid joints to the foundations.

The adjacent "V"-shaped supports as well as the R/C columns of the two bridge structures are connected to separate R/C fundaments.

\section{METHOD OF CONSTRUCTION}

The steel superstructure in the form of an open steel cross-sections (or boxes, alternatively) were prefabricated in the shipbuilding plant "Stoyan Pavlov" in Varna.

The parts of the steel structure were cut out by a CAD/CAM system according to the final detailed drawings.

Full corrosion protection was provided at the construction site. The structure of the bridge was divided into separate sections (Figure 5) with such dimensions and weight that they could be transported by trucks about $500 \mathrm{~km}$ from Varna on the Black Sea coast to Sofia. 


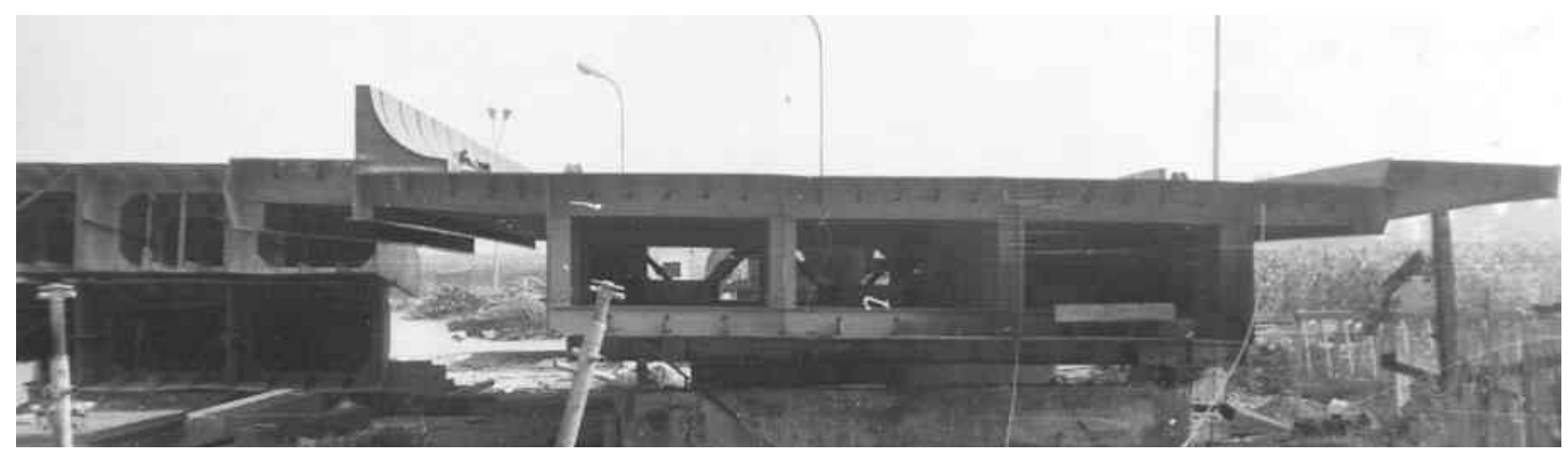

Figure 5. Triple-Box Section of the Bridge Deck

In longitudinal direction five separate sections formed the curvilinear shape of the bridge following the geometry of the road. In transversal direction each of the two decks was also assembled from five separate sections. The "V"-supports were delivered to the site as block elements built in their design dimensions (Figure 6).

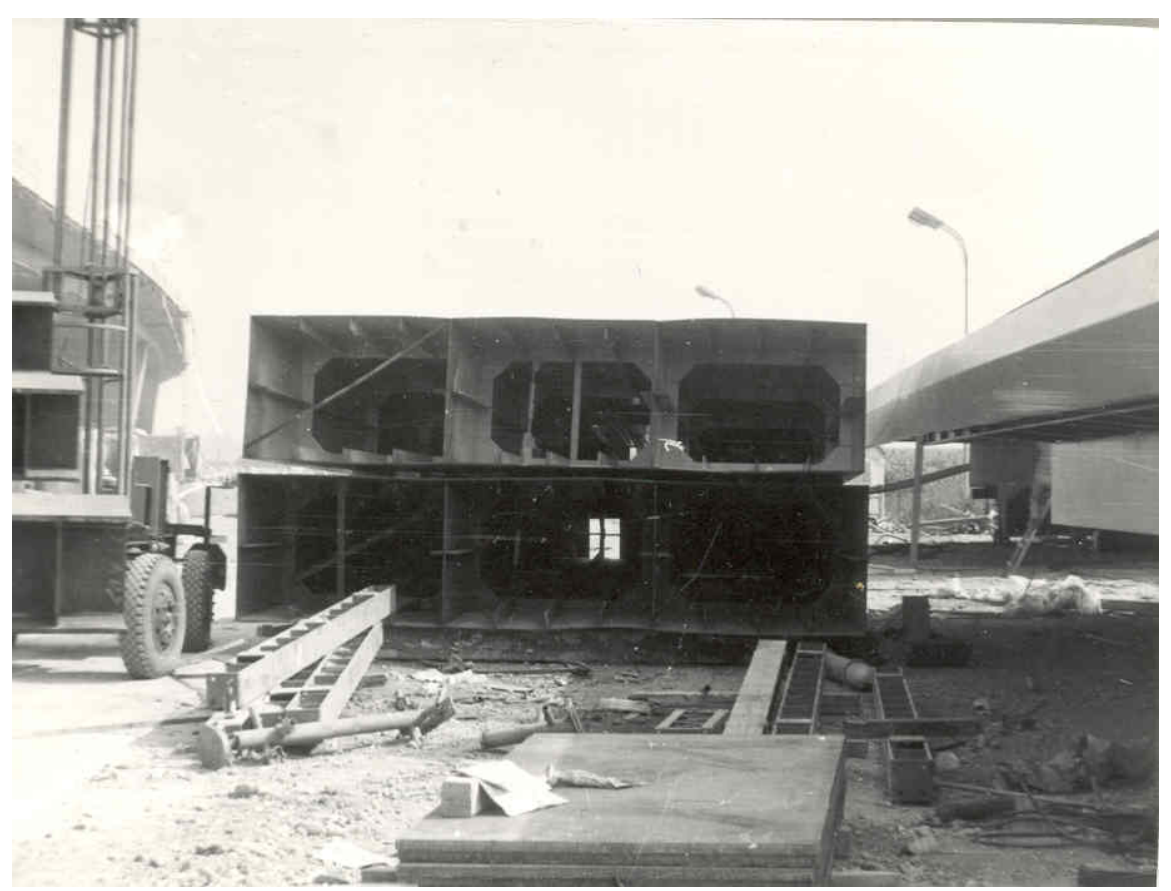

Figure 6. "V"- Supports at the Construction Site

The construction of the bridge started from the middle and continued to both ends simultaneously. The middle sections of the two carriageways with a length of $16.426 \mathrm{~m}$ were placed over the previously erected middle R/C columns and a temporary steel structure as shown in Figure 7. 


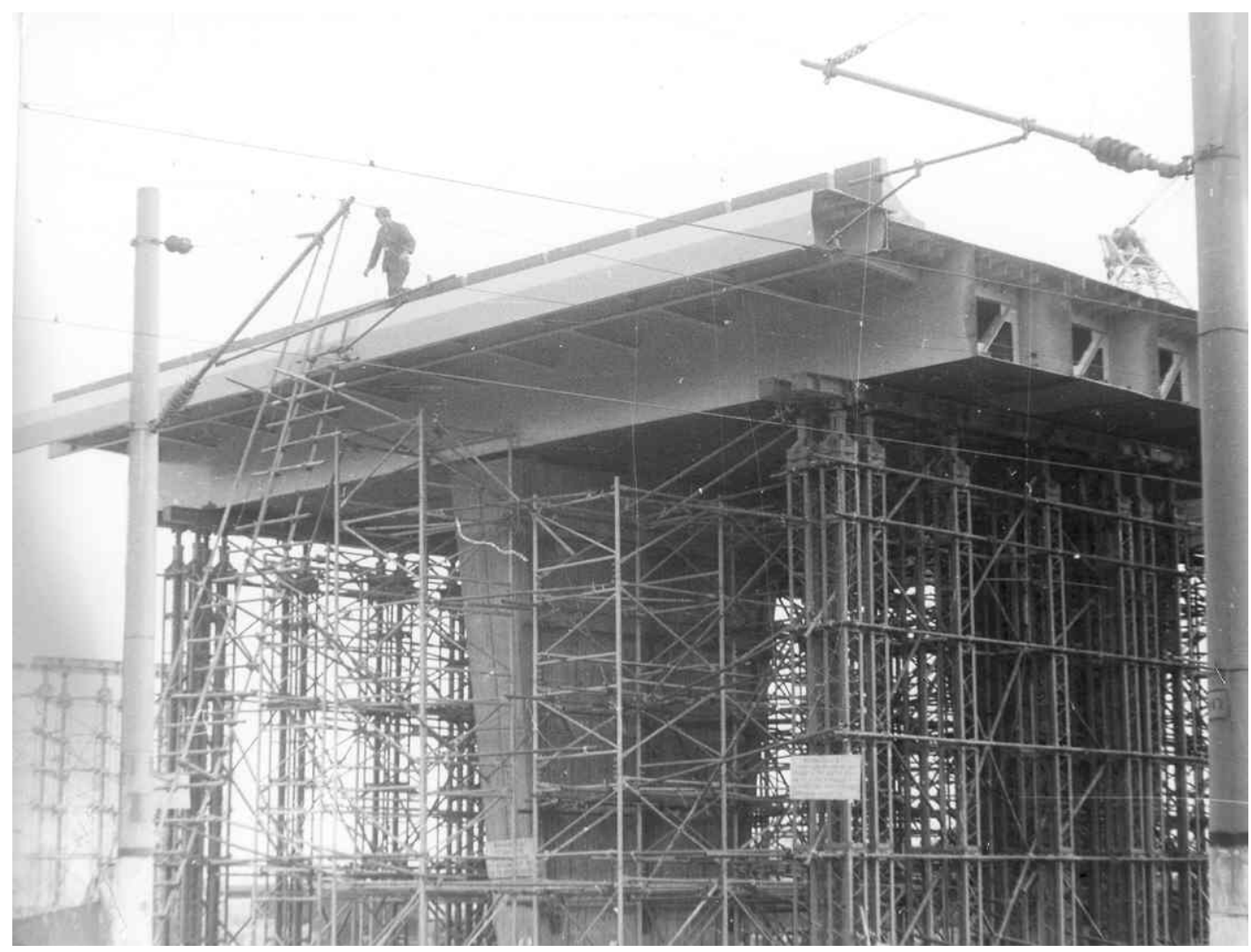

Figure 7. Assembly of the Central Section on the Middle Column and the Temporary Steel Structure

The girders were taken to the construction site (see Figure 8) where they were lifted into their final position with a mobile crane "Demag" shown in Figures 9 and 10.

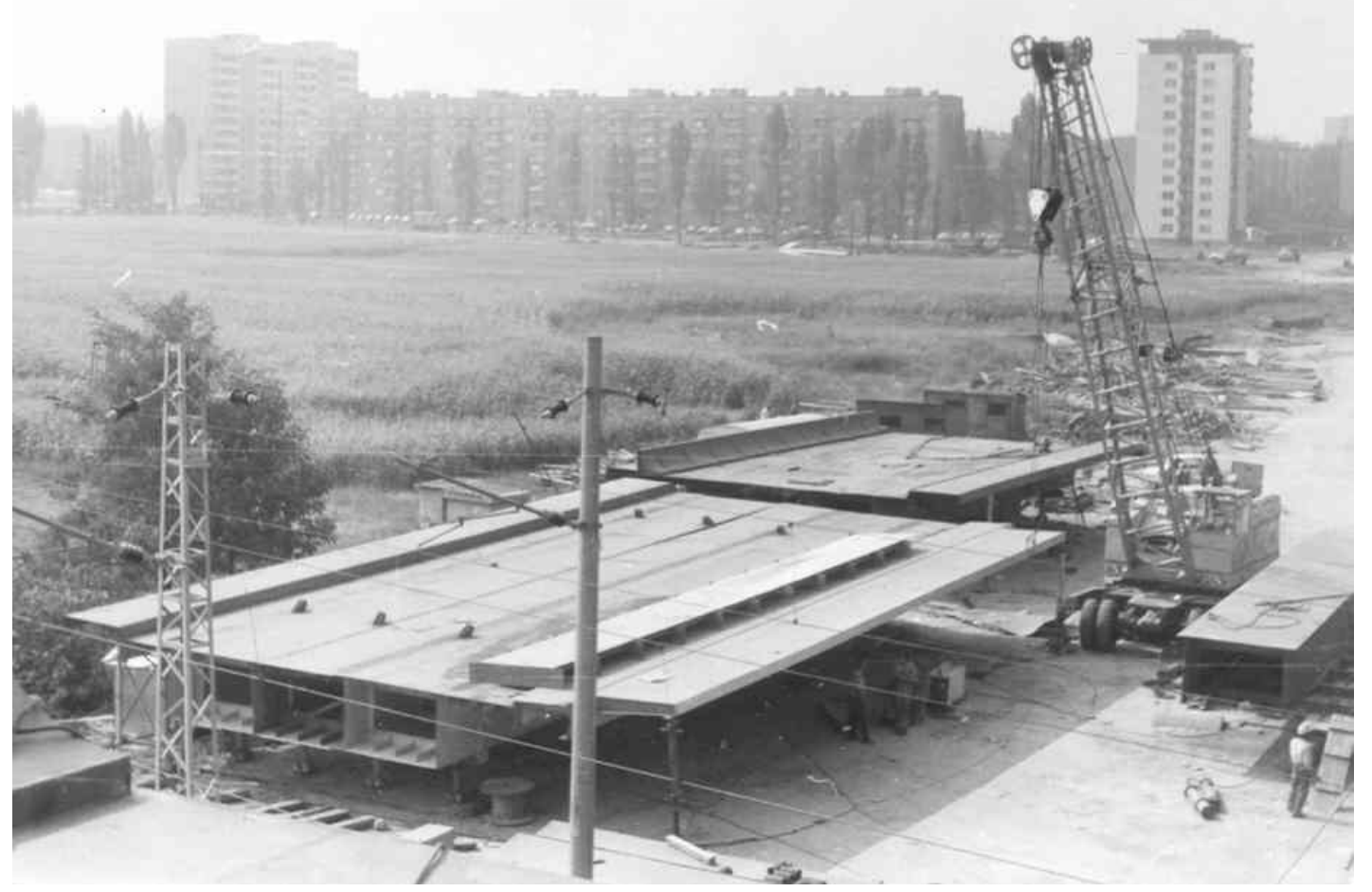

Figure 8. Orthotropic Bridge Storage Yard 


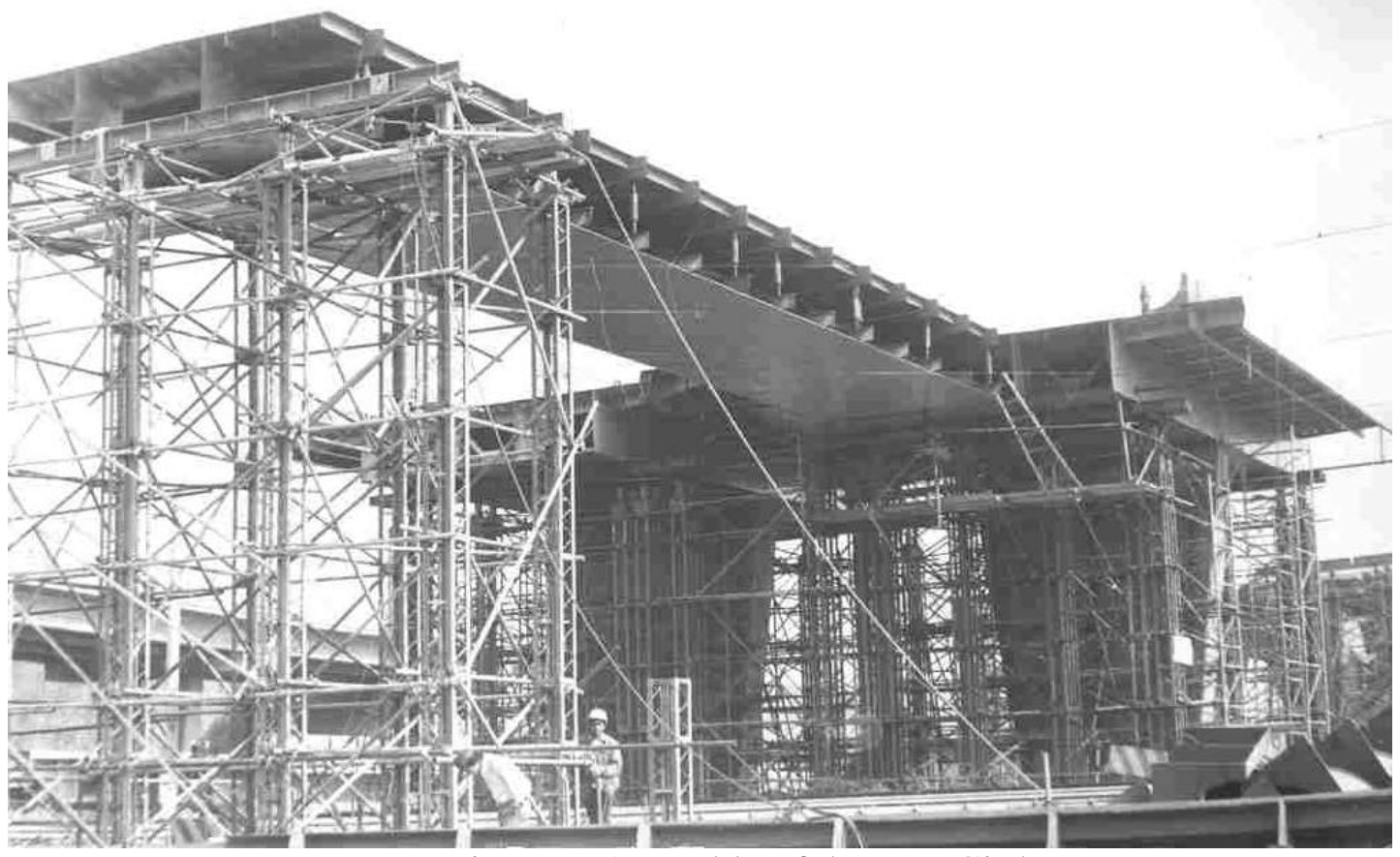

Figure 9. Assembly of the Box Girders

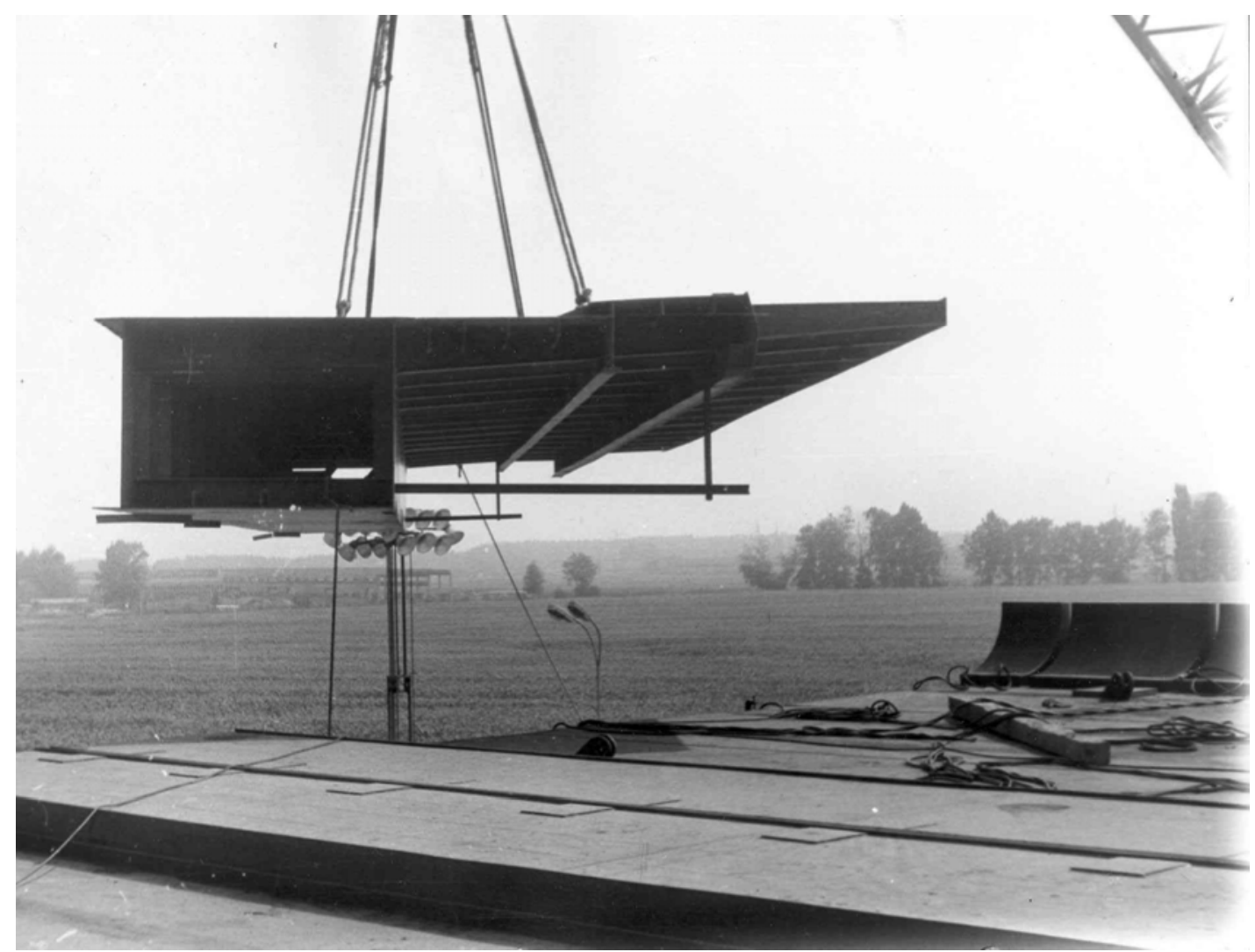

Figure 10. Composition of a Separate Section

The "V”-supports were erected using a temporary tubular scaffolding (Figure 11). 


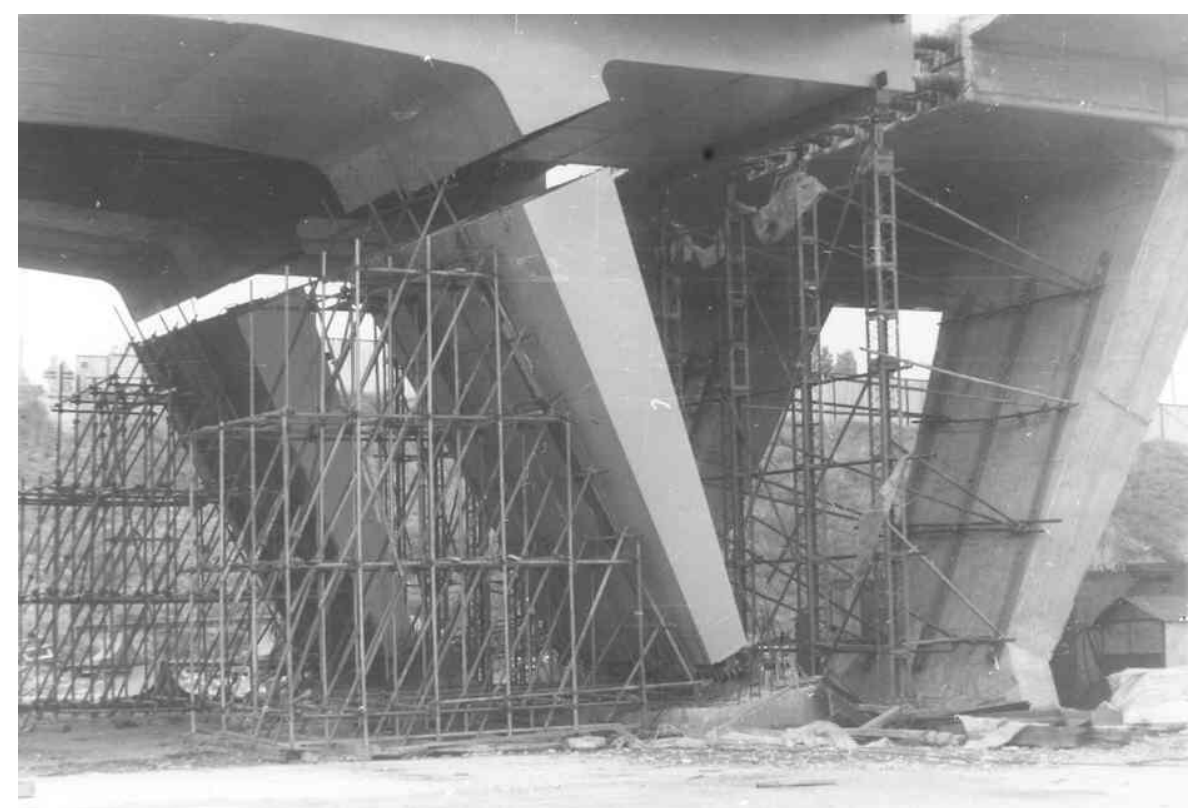

Figure 11. Assembling of the Steel "V”- Supports

In this position, the "V"-shaped supports were mounted onto the concrete bases by means of steel bearings and connected with precision to the lower orthotropic steel deck of the bridge (see Figure 12).

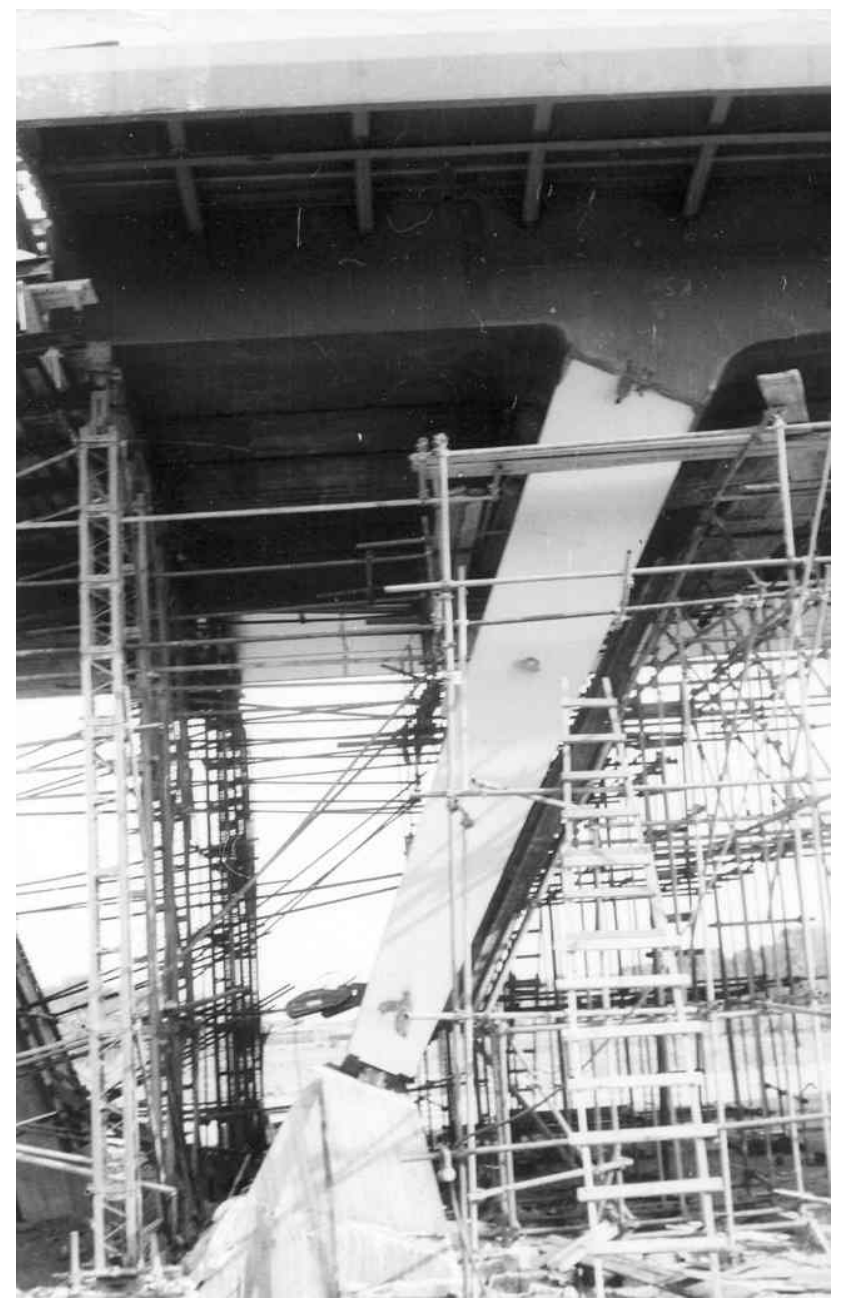

Figure 12. Connection of the "V"- Support to the Lower Orthotropic Steel Deck 
The concrete foundation was completed up to the level of the steel bearings after connecting the steel supports to the bridge deck (see Figure 13).

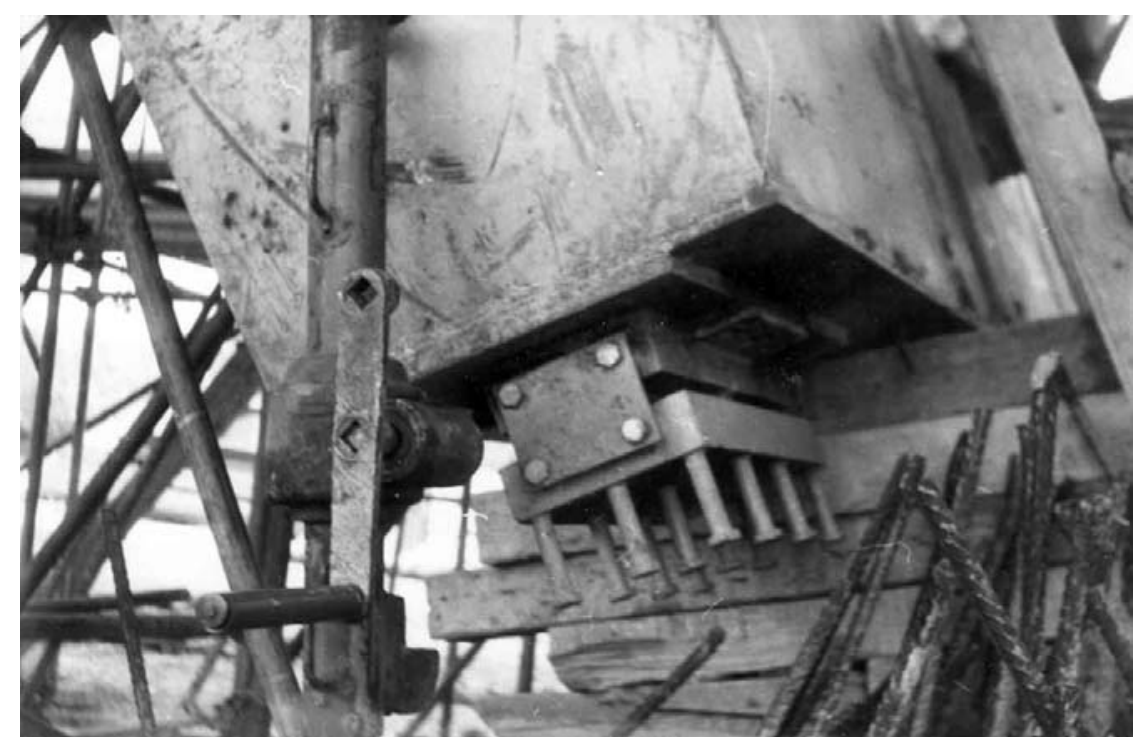

Figure 13. Cylindrical Steel Bearing of the "V"- Supports before Concrete Casting

The separated sections were connected to each other by welding. The adjustments between sections are realized by special steel cantilevers and hydraulic jacks (Figure 14).

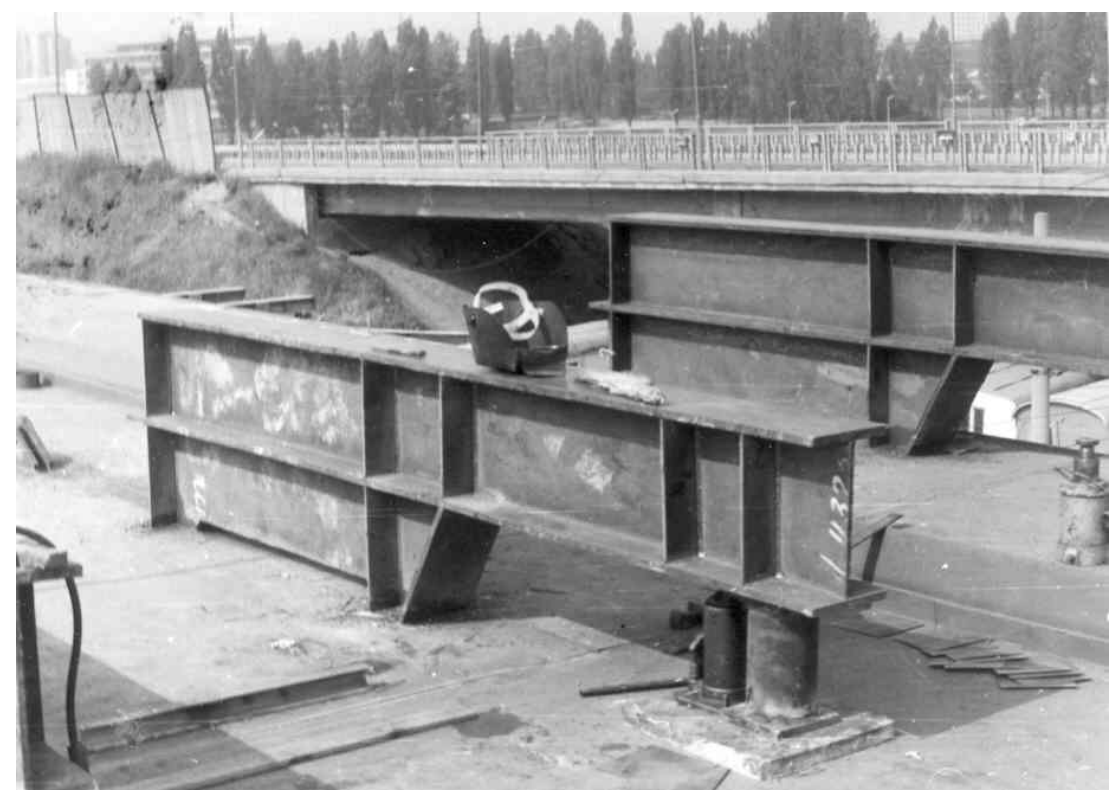

Figure 14. The Fitting Process by Steel Cantilevers and Hydraulic Jacks

A trial assembly of the separate sections was made at the construction site in order to ensure precise connections between them (Figure 8).

The total weight of all structural elements was 630 tons. All adjustments and connections were carefully supervised by chief designer Dr. eng. B. Bankov and the assembly process was completed in 12 days (Figure 15).

The railway had to be blocked during the night when the prefabricated steel elements were being installed. 


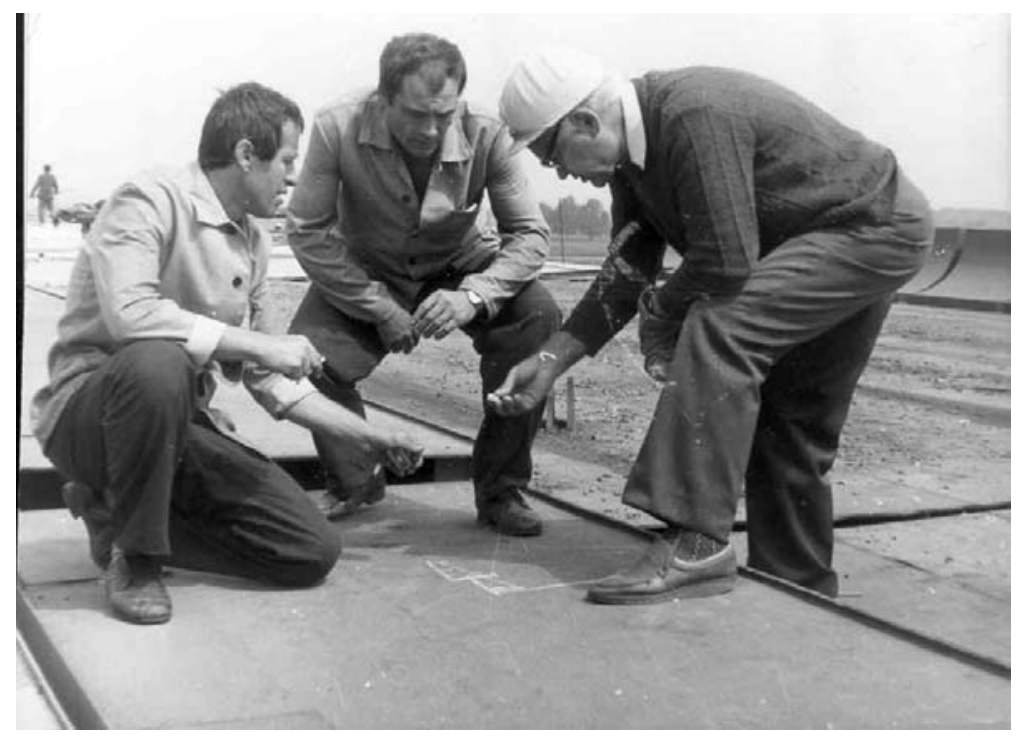

Figure 15. Supervision of the Assembly Process

\section{LOADS, ANALYSIS AND DESIGN}

In the preliminary design the structure was analyzed and designed manually as an orthotropic plate carried by a two-bay frame with hinged supports (Cornelius [1], Hawranek and Steinhardt [2], Pelikan and Esslinger [3]). The frame can be treated as a "Gazelle"-type structure with two spans, $38.825 \mathrm{~m}$ each, and two cantilevers of $6 \mathrm{~m}$ long. The calculations include all actions of:

- dead loads - self-weight of structural components;

- live loads - uniformly distributed $3.0 \mathrm{kN} / \mathrm{m}^{2}$ on the footway;

- $\quad$ snow loads $-1.0 \mathrm{kN} / \mathrm{m}^{2}$;

- moving loads - N30, NK80 according to DIN 1072;

- break forces - obtained from two columns of trucks N30 and equal to $540.0 \mathrm{kN}$;

- wind loads - by unloaded bridge $-2.5 \mathrm{kN} / \mathrm{m}^{2}$; by loaded bridge $-1.25 \mathrm{kN} / \mathrm{m}^{2}$;

- temperature loads $- \pm 40^{\circ} \mathrm{C}$;

- earthquake loads - according to Bulgarian code 1972;

NK80 was presented by four concentrated forces of $200 \mathrm{kN}$ each with a distance between them of $1.20 \mathrm{~m}$.

The moving loads were transmitted to the transversal beams by longitudinal ribs. The loads on the transversal beams were obtained from the influence lines for vertical support reactions and bending moments of multi-span continuous beams with rigid supports.

The bending moments of the transversal beams and the longitudinal ribs were obtained as moments in an orthotropic plate according to the Cornelius theory (Cornelius [1]) and verified by the theory of Pelikan and Esslinger (Pelikan and Esslinger [3]). The maximum bending moments in the middle of the beams and ribs were obtained by influence surfaces (Hawranek and Steinhardt [2]).

The total stresses in the upper deck were the sum of the stresses obtained from the analysis of the top flanges of the transversal beams, the longitudinal ribs and the main girders.

For the purpose of the detailed design, the bridge structure was modelled as a 3D frame and analyzed by the computer program STRUDL (Manuals of STRUDL-II [4]), based on the finite element method. 
The structure was designed in accordance with German Codes (DIN 1073 [5], DIN 1079 [6], DIN 4101 [7]) for all loads (DIN 1072 [8]) acting on the bridge during the assembly process and exploitation. Additionally, design checks were manually performed for some structural elements, taking into account several important characteristics (Bankov et al. [9]). The effect of the horizontal curvature on strains and internal forces was analyzed. The pure torsion and the restricted torsion of the thin-walled box steel girder were considered. The inclined "V"-shaped supports with variable cross-sections were analyzed according to the second order theory. The axial force, the shear force and the bending moments obtained from the analysis were taken into account in the design of the structure. It is assumed that the constitutive Prandtl's law holds for steel. The stability of the critical sections in all phases is ensured using DIN 4114 (DIN 4114 [10]) and Kloeppel design tables (Kloeppel [11]).

\section{USED MATERIALS, MANUFACTURE AND ERECTION OF THE BRIDGE}

The upper and the lower deck of the box structure, the transversal beams and the longitudinal ribs of the orthotropic plates, the webs and the stiffeners of the main girders, the "V"-shaped supports were made from high-strength steel 09G2BM ( $\left.\mathrm{f}_{\mathrm{y}}=330 \mathrm{MPa}\right)$, produced in Bulgaria. The footway structure, the structure between two carriageways, the safety borders and the parapets were made from steel V St3 $\left(f_{y}=210 \mathrm{MPa}\right)$. All components and joints of the bridge structures were welded (Figure 8). The construction work on the bridge was completed in a short period of time. The design process started on 05/10/1982 and finished on 30/03/1983. The delivery of steel for the structure began on $05 / 05 / 1983$. The erection and assembly of the bridge took only six months. The bridge was opened for traffic on October 4th, 1983.

\section{PAVEMENT AND WATERPROOFING}

The pavement consists of a $3 \mathrm{~mm}$ waterproofing, which is a polymer epoxy resin layer, one layer of medium grained mastic asphalt carpet made of modified $45 \mathrm{~mm}$ thick asphalt and a final layer of 45 mm thick asphalt. The effectiveness of the connection between the steel structure and the epoxy resin was guaranteed by sand blasting the steel deck. Surfaces needed to be sanded in order to remove rust and any other debris and impurities. An additional steel reinforcement ensured the composite action between the steel deck and the pavement (Figure 16)

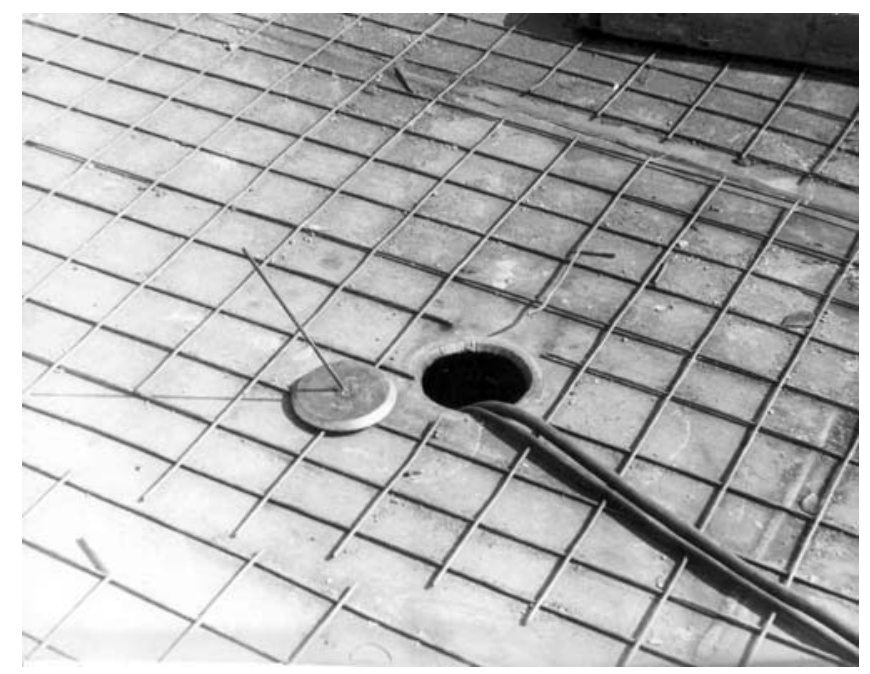

Figure 16. A Steel Reinforcement Welded to the Bridge Deck 


\section{NONDESTRUCTIVE TESTING OF MATERIALS AND WELDS}

The materials used for the structural elements were subject to non-destructive testing by means of an ultrasonic device before cutting the steel sheets. The predominant defect in structural steel is delamination of the sheet edges. $100 \%$ of the welds between the separate sections are tested "in situ” by X-rays.

\section{STRUCTURAL TESTING}

The static and dynamic tests were performed during the process of assembly of the bridge steel structure.

The testing load consisted of lorries loaded with military tanks, which provided $100 \%$ of the design load. The response of the structure was controlled by measuring deflection and strains in the middle of the span. The dynamic response of the bridge in longitudinal direction was measured by simulation of an impulse, caused by the motion of a particular vehicle along the bridge at various speeds.

The maximum value of deflection in the middle of span was $28 \mathrm{~mm}$. The series of measurements of the local strains (stresses) showed an acceptable uniform distribution of the stress field over the cross-section for both symmetrical and asymmetrical positions of the test load.

After unloading the structure it was established that the stress response and the deformation response of the bridge were elastic. The tests showed that the roadway orthotropic bridge in Sofia was able to bear traffic loading in compliance with design codes [4], [5].

\section{SUMMARY}

The steel orthotropic bridge over the railway Sofia-Varna is an example of an effective structural method for medium span bridges. It is applicable for spans of 20-60 m considering that the prefabricated steel components are transported by road. To achieve of design versatility with the use of steel as a building material, a visually attractive structure could also be created.

Since the region of Sofia is an active earthquake area, seismic codes had to be considered. However, the structure was proven to be ideal for earthquake regions. The superstructure with small mass, together with the inclined supports and columns formed a structure with excellent stiffness.

A high level of precision was required during the process of construction, since much of the work had to be carried out in advance under the factory conditions. The technical tests proved the high quality of the structure. This important and complex bridge has been operating successfully for more than 20 years (see Figures 17, 18). 


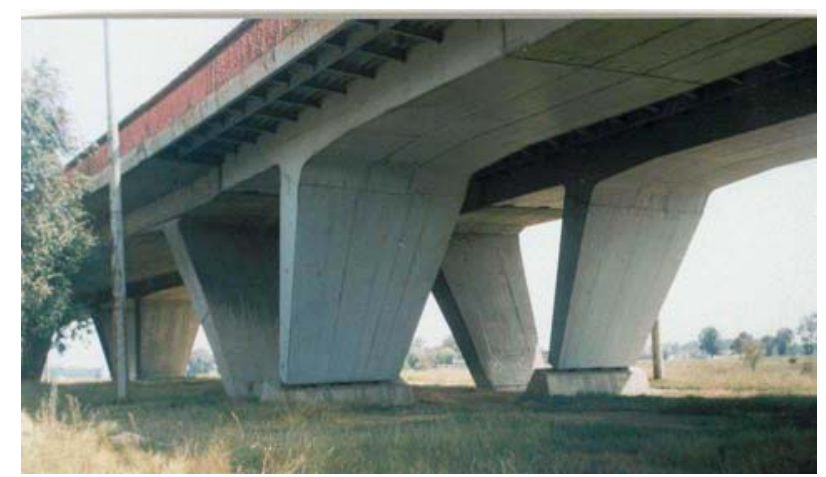

Figure 17. A View of the Steel and Concrete Parts of the Bridge

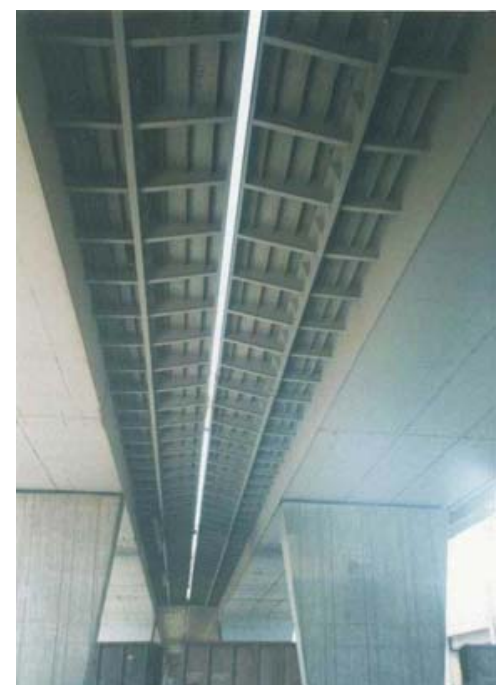

Figure 18. A View from Beneath the Orthotropic Bridge

\section{REFERENCES}

[1] Cornelius, W., "Die Berechnung der ebenen Flaechentragwerke mit Hilfe der Theorie der orthogonal-anisotropen Platte”, Der Stahlbau, 1952, Vol. 21, pp. 21-24; 43-48; 60-64.

[2] Hawranek, A. and Steinhardt, O., “Theorie und Berechnung der Stahlbruecken”, Berlin-Goettingen-Heidelberg, Springer Verlag, 1958.

[3] Pelikan, W. and Esslinger, M., "Die Stahlfahrbahn, Berechnung und Konstruktion", Ausburg-Nuernberg, MAN-Forschungsheft No 7, 1957.

[4] “Manuals of the Computer Program STRUDL-II”, Massachusetts Institute of Technology, Massachusetts, 1982.

[5] DIN 1073, “Staehlerne Strassenbruecken, (Berechnungsgrundlagen)”, 1973.

[6] DIN 1079, "Staehlerne Strassenbruecken, (Grundsaetze fuer Bauliche Dirchbildung)", 1979.

[7] DIN 4101, “Geschweisste staehlerne Strassenbruecken, (Berechnung, Bauliche Durchbildung und Ausfuerung)", 1970.

[8] DIN 1072, “Strassen und Wegbruecken, (Lastannahmen)”, 1967.

[9] Bankov, B., Partov, D., Hristov, H., Tsvetkov, V., Bankova, I., Hristov, V., Hadjinikolov, L. and Bankov, L., "Detailed Structural Design Project of the Orthotropic Bridge to the Airport in Sofia”, 1983, (in BG).

[10] DIN 4114, "Stabilitaetsfaelle”, 1961.

[11] Kloeppel, K., “Beulwerte ausgesteifer Rechteckplatten”, W. Ernst, I-1960, II-1968. 